\title{
INDÚSTRIA ERVATEIRA NO ESTADO DO PARANÁ II - FORNECIMENTO DE MATÉRIA-PRIMA ${ }^{1}$
}

\author{
Erva-Mate Industrial Sector in Parana State II - \\ Raw Material Supply
}

\author{
Agenor Maccari Jr. ${ }^{2}$ \\ Marlene R. de Queiroz ${ }^{3}$ \\ Lauren D. B. Roncato Maccari ${ }^{4}$ \\ Neusa G.A. Rucker ${ }^{5}$
}

\section{Resumo}

O fornecimento de erva-mate verde pode ser considerado o ponto mais importante para a indústria ervateira, capaz de definir a localização das unidades industriais. A produção de erva-mate verde no Paraná se dá em ervais com diferentes características, influenciando a qualidade da matéria-prima e do produto final. Tal situação toma essencial avaliar a procedência e características do fornecimento de matéria-prima para uma efetiva análise do setor industrial ervateiro. Este trabalho faz um diagnóstico sobre o fornecimento de ervamate verde para as ervateiras do Paraná. Um questionário foi aplicado nas ervateiras paranaenses em atividade na safra 2003. Os resultados permitiram traçar um perfil sobre a época de colheita, fomecedores de matériaprima, tipo de erval e aspectos relacionados ao rendimento industrial.

Palavras-chaves: Erva-mate; Época de colheita; Ilex paraguariensis.

\section{Abstract}

The green erva-mate supply (raw material) can be considered the mostimportant pointfor the "mate" industry, since it defines the location of the industrial units. The green erva-mate production in Parana State occurs in fields with different characteristics, which influences the quality of raw material and the final product. This fact shows the importance of origin and raw material supply characteristics during the analysis of the ervamate industrial sector. This work shows a picture of the green erva-mate supply in Parana erva-mate industries during the 2003 harvest. The results of an inquiry are presented, and allowed to draw a profile about time of harvest, raw material suppliers, cultivation characteristics and some aspects related with industrial income.

Keywords: Erva-mate; Time of harvest; Ilex paraguariensis.

1 Extraído da dissertação de doutorado do primeiro autor, a qual foi apresentada ao Curso de Doutorado em Engenharia Agrícola, Universidade Estadual de Campinas - UNICAMP.

2 Eng. Agrônomo, Doutor, Professor do Departamento de Solos e Engenharia Agrícola, Universidade Federal do Paraná, Rua dos Funcionários, 1540, Curitiba-PR, 80.035-050, maccari@ufpr.br

3 Eng. a Agrícola, Doutora, Professora da Faculdade de Engenharia Agrícola, Universidade Estadual de Campinas (FEAGRI/ UNICAMP) - marlene@agr.unicamp.br

4 Eng. a Agrônoma, Doutora, Empresa Cambona Tecnologia Agroindustrial, lauren.roncato@uol.com.br

5 Socióloga, Doutora, Departamento de Economia Rural, Secretaria de Estado da Agricultura e do Abastecimento do Paraná DERAL/SEAB, neusagar@pr.gov.br 


\section{Introdução}

O processamento de alimentos não pode ser dissociado da sua produção no campo, uma vez que a qualidade do produto final está diretamente associada à qualidade da matéria-prima. Isso se aplica também à erva-mate para chimarrão, cujas características são dependentes das caracteństicas da erva-mate verde. Estudos têm sido realizados nesse sentido, como o de Cardozo Junior et al. (2003), que analisaram os fatores características da planta e composição química, e os de Brumovsky et al. (2003); Reissmann et al. (1985), que estudaram a época do ano para colheita e sua composição química, e INSTITUTO DE QUÍMICA AGRÍCOLA (1944), que estudou a região de procedência da erva-mate verde e suas características químicas.

Com a constante busca de qualidade e otimização de operações e unidade se torna essencial estudar cada vez mais a matéria-prima e seu processo de produção agrícola. Por isso, é necessário avaliar as principais características do fornecimento de erva-mate verde para a indústria ervateira paranaense. A delimitação do Estado do Paraná como foco do estudo se deve ao fato de ser esse o maior produtor de erva-mate do Brasil. Como o Estado possui mais de 100 indústrias ativas e a região ervateira ocupa vasto território, é plausível se encontrar variações entre regiões produtoras de erva e entre unidades ervateiras.

A análise do fornecimento da matéria-prima pode trazer informações para caracterização do setor industrial ervateiro no Estado e do produto gerado, neste caso, a erva-mate para chimarrão, produto que absorve mais de $90 \%$ da erva-mate colhida (PARANÁ, 1997). Tendo em vista os inúmeros fatores da produção agrícola que podem interferir na qualidade do produto, é necessário selecionar os principais fatores para análise.

\section{Época de colheita}

A época de colheita da erva-mate é um fator apontado como de grande reflexo sobre a qualidade do produto. Apesar disso, a colheita não se restringe a uma época específica do ano, pois algumas unidades trabalham durante 0 ano inteiro. A definição da época de colheita, e conseqüentemente dos meses de atividade das ervateiras, se dá em virtude de dois fatores:
1 - Aspectos da fisiologia da planta de erva-mate: a erveira entra em repouso fisiológico no inverno, época em que a poda causa menores danos à planta, permitindo rápida regeneração. Importante lembrar que há variações na composição química da planta em função da época do ano, indicando que a colheita em diferentes épocas gera produtos diferentes do ponto de vista químico/nutritivo.

2 - Requisitos do mercado: dentre os atributos da erva-mate para chimarrão, a cor verde é um dos mais valorizados (DUARTE; WASZCZYNSKYJ, 2000; RUCKER, 2000). Como a cor muda durante o armazenamento da erva-mate, é necessária constante reposição do produto nos pontos de venda. Isto implica em oferta durante todos os meses do ano de produto de cor verde intensa, característica da erva-mate recém-processada.

A época de colheita é um dos pontos interessantes na exploração da erva-mate, visto ter inúmeras implicações. Mazuchowski; Rücker (1996; 1993) e Andrade (1999) fazem diversas considerações a este respeito:

- O período de maio a setembro é o ideal para a colheita da erva-mate, em especial entre junho a agosto, pois ainda não há brotação, as folhas estão maduras e a erveira está em repouso fisiológico. Segundo Valduga et al. (2003), por causar menores danos à erveira, boa parte dos produtores colhe a erva neste período, aumentando a oferta do produto, que chega a $65 \%$ do volume total, fazendo desta a principal época de colheita, período denominado de safra.

- A safrinha ocorre nos meses fora do período de safra e tem como maiores empecilhos fatores climáticos como geadas precoces e insolação que podem prejudicar o bom desenvolvimento da planta podada. Porém, há interesse por parte das indústrias na colheita durante a safrinha, para otimizar o uso da estrutura de processamento e o fluxo de caixa. A colheita de safrinha se concentra nos meses de dezembro a fevereiro.

Um levantamento feito no Estado do Paraná mostrou que a época de colheita da ervamate não era influenciada pelo nível tecnológico do sistema de produção, sendo a colheita da safra realizada nos meses de junho a setembro (MAZUCHOWSKI; RUCKER, 1993). Em outro levantamento, realizado por Hoppe et al. (1996), foram entrevistados agricultores do Estado do Rio Grande do Sul, dos quais $33 \%$ realizavam colheita na safri- 
nha, durante os meses de dezembro, janeiro e fevereiro, com preferência para o mês de janeiro.

Como a planta de erva-mate possui comportamento fenológico associado às estações do ano, têm-se grandes diferenças, em especial quanto à maturação e atributos organolépticos, entre a planta colhida no inverno e a planta colhida no verão. Essas diferenças afetam o rendimento desfrute industrial, o que pode afetar significativamente os custos de produção.

\section{Tipo de erval}

A exploração da erva-mate tem sido realizada há séculos e os sistemas de produção têm sofrido grandes variações, sendo difícil definir um sistema de cultivo ou tipo de erval padrão. É difícil traçar características gerais para os ervais e para os sistemas de produção também, pela grande área ervateira e sua conseqüente diversidade nas práticas de cultivo. Esse é o caso dos ervais de ocorrência natural e os de plantio.

A constante exploração da erva-mate e o aumento na demanda pelo produto levaram a uma maior pressão sobre os ervais nativos ou sombreados. Para garantir o abastecimento surgiram os ervais plantados a pleno sol, solteiros ou com culturas permanentes e sazonais intercaladas. Entretanto, dados do Deser (2001) mostram que a produção de erva-mate no Brasil ainda está centrada em ervais sombreados, que respondem por mais da metade $(57,29 \%)$ da produção. A participação de ervais nativos na produção mostra diferenças marcantes entre os Estados.

No caso do Paraná, maior produtor brasileiro, os ervais nativos representam $3 / 4$ da área com erva-mate. Este valor pode ser ainda maior, pois Andrade (1999) cita que os ervais nativos ocupariam $91,2 \%$ da área explorada no Paraná, o que corresponderia a aproximadamente 258 mil ha. Nessas circunstâncias, considerando a participação dos ervais nativos na produção, o Paraná merece destaque, pois responde por mais da metade da produção brasileira de "erva-mate nativa", abastecendo indústrias de outros Estados.

A origem da matéria-prima proveniente de ervais nativos ou de ervais cultivados, é um tópico interessante na produção da erva-mate, tanto do ponto de vista técnico quanto econômico. Essa é a principal característica de diferenciação dos ervais brasileiros e argentinos, pois na Argentina a totalidade dos ervais em produção é cultivada, a pleno sol, contrapondo-se ao Brasil onde há grandes áreas com ervais nativos, sombreados.

Há, entre os ervateiros, produtores e industriais, um senso comum de que a erva-mate de ervais nativos ou sombreados apresenta melhores atributos do que o produto vindo de ervais cultivados ou de pleno sol. Essa informação tem fundamento, se consideradas as distintas características edafo-climáticas em cada um desses sistemas afetando o desenvolvimento das plantas. $\mathrm{O}$ efeito do ambiente sobre as plantas de erva-mate foi tema de estudos como os de Boeger et al. (2003), Coelho et al. (2000) e Mazuchowski et al. (2003). Assim, variações no ambiente influenciariam as características da matéria-prima e dos produtos elaborados (MAZUCHOWSKI, 2000).

\section{Material e métodos}

Empregando dados de diferentes fontes (instituições), foi criado um banco de dados sobre as ervateiras paranaenses, com dados de identificação e localização das unidades industriais em cada município e região do Estado do Paraná. Os municípios listados foram visitados durante os cinco meses de safra, de maio a setembro de 2003, para identificação das ervateiras em atividade no período.

As ervateiras ativas foram visitadas para aplicação de um questionário elaborado previamente elaborado e validado a campo. Esse formulário foi empregado em entrevistas com proprietários e gerentes das unidades industriais. $\mathrm{O}$ questionário continha questões sobre o volume de ervamate comprado nos últimos três anos de atividade da empresa, o volume comprado a cada mês e a origem do produto quanto ao tipo de erval explorado. Os dados obtidos referentes aos municípios foram agrupados por Núcleo Regional, padrão adotado pelo Governo do Estado do Paraná.

\section{Resultados e discussão}

\section{Época de colheita}

Os dados obtidos com o formulário mostraram que a colheita da erva-mate vem sendo feita durante todos os meses do ano. Tornou-se ne- 
cessário, então, avaliar se o volume colhido durante a safrinha seria significativo. Para tanto, 0 questionário continha uma questão focando o volume processado (\%) no período de safra e de safrinha. As respostas obtidas foram transformadas em valores médios para cada núcleo e apresentados na Tabela 1.

A Tabela 1 mostra que a maior parte do volume processado pelas ervateiras do Paraná provém do período de safra, média de $68 \%$. Além disso, indica diferenças entre núcleos. Um aspecto relevante observado é que os núcleos com maior número de unidades processam a maior parte de sua produção durante a safra. Ao se calcular a média ponderada, levando em conta o número de unidades em cada Núcleo, o processamento na safra responderia por $71 \%$ da produção de cada unidade. Porém, cabe lembrar que os núcleos com maior número de cancheadoras estão localizados na região de maior oferta de matéria-prima.

Assim, os núcleos que absorvem grande parte da erva-mate paranaense (cerca de 2/3) processam a maior parte da sua produção (cerca de 3 / 4) durante um período de tempo restrito, 3 a 4 meses. Esse regime de trabalho aponta para uma grande ociosidade da estrutura ao longo do ano.

\section{TABELA 1 - Volume de erva-mate processado (\%) durante a safra e a safrinha nos núcleos regionais.}

Table 1 - Volume of erva-mate processed (\%) in two different harvesting time and divided by regional nucleus.

\begin{tabular}{|l|c|c|c|}
\hline \multirow{2}{*}{ Núcleo Regional } & \multicolumn{2}{|c|}{ Volume processado (\%) } & Número de ervateiras \\
\cline { 2 - 3 } cancheadoras no Núcleo
\end{tabular}

As possíveis explicações para este comportamento de concentração espacial e temporal da colheita e processamento da erva-mate são:

- Os núcleos com menor número de unidades industriais estão localizados em áreas de menor oferta de erva-mate verde; são núcleos que atendem principalmente o mercado local, tendo em vista a pequena produção e, em função da demanda de erva verde durante todo o ano, há necessidade de colheita durante a safrinha;
- Os núcleos com maior número de unidades estão na região de maior produção de ervamate verde; o número de unidades e o volume processado suprem o mercado local e um excedente de erva cancheada é direcionado ao mercado externo. O padrão de produto para exportação requer o estacionamento da produção, permitindo a colheita durante a safra, período com vantagens técnicas. Além disso, parte desta produção é armazenada para comercialização no Brasil, na forma de erva-mate de cor amarela (estacionada). 
Há exceções, casos como o núcleo de Curitiba, com poucas ervateiras, mas com colheita predominante na safra. $\mathrm{O}$ tamanho das unidades localizadas nesse núcleo e a proximidade da região maior produtora de matéria-prima podem influenciar o comportamento neste aspecto.

\section{Origem da matéria-prima}

O questionário buscou avaliar a relação entre o produtor rural (fornecedor) e a indústria ervateira. Os dados obtidos são apresentados na Tabela 2, cuja análise fornece referências sobre 0 grau de dependência entre os dois elos da cadeia produtiva, fornecedor e indústria, bem como propicia subsídios para a definição de ações direcionadas à melhoria da qualidade da matéria-prima no campo aos produtores rurais.
Os dados da Tabela 2 mostram que a relação entre fornecedor de matéria-prima no Paraná é uma característica regional, variando para cada núcleo. Os dados mostram ainda que a integração vertical não é acentuada no setor ervateiro paranaense no que se refere à produção agrícola, pois apenas $22,2 \%$ da matéria-prima processada vêm de erval próprio.

Como a maior parte da matéria-prima é comprada de fornecedores (cerca de 80\%), cabe avaliar o vínculo entre esses e a indústria. Os dados indicam que o estabelecimento de parcerias não é uma característica marcante do setor ervateiro paranaense. Apenas $18,0 \%$ da matériaprima são provenientes de ervais de parceiros, embora haja expressiva variação entre núcleos regionais.

\section{TABELA 2 - Origem da erva-mate verde.}

Table 2 - Origin of the raw material.

\begin{tabular}{|l|c|c|c|}
\hline \multicolumn{1}{|c|}{ Núcleo Regional } & $\begin{array}{c}\text { Erval próprio } \\
\text { (\%)* }\end{array}$ & $\begin{array}{c}\text { Erval de parceiros } \\
\text { (\%) }\end{array}$ & $\begin{array}{c}\text { Erval de terceiros } \\
\text { (\%) }\end{array}$ \\
\hline Cascavel & 17,5 & 12,5 & 70,0 \\
Curitiba & 48,8 & 20,0 & 31,2 \\
Francisco Beltrão & 1,0 & 69,0 & 30,0 \\
Guarapuava & 27,2 & 12,1 & 60,7 \\
Irati & 35,0 & 31,0 & 34,0 \\
Ivaiporã & 25,0 & 11,3 & 63,7 \\
Laranjeiras do Sul & 5,9 & 15,0 & 79,1 \\
Pato Branco & 20,0 & 28,8 & 51,2 \\
Ponta Grossa & 23,2 & 61,0 & 15,8 \\
União da Vitória & 18,0 & 6,0 & 76,0 \\
Estado do Paraná & 22,2 & 18,0 & 59,8 \\
\hline
\end{tabular}

*\% do volume processado.

O baixo volume de erva-mate de ervais de parceiros pode indicar tanto uma boa oferta de matéria-prima, não havendo preocupação da indústria em garantir fornecimento, quanto uma alta demanda, podendo o agricultor optar pelo melhor preço no momento da venda. Esse ponto foi contemplado em outra questão do questionário, onde os resultados podem esclarecer tais dúvidas. De todo modo, a ausência de um compromisso ou de fidelidade entre fornecedor de matéria-prima e indústria é confirmada pelo alto percentual da produção que vem de ervais de terceiros. 


\section{Tipo de erval}

Um dos aspectos mais polêmicos da produção de erva-mate diz respeito à relação entre tipo de erval e qualidade do produto. Há muita controvérsia sobre a influência do ambiente quanto à luminosidade e a qualidade da erva-mate. Além disso, o declínio dos ervais tem reduzido a produção de erva-mate nos ervais nativos/sombreados. Por isso, a necessidade de se levantar informações sobre a origem da erva-mate e os resultados obtidos no questionário (Tabela 3) pode levar a interessantes considerações.

Os dados mostram que a maior parte (60\%) da erva-mate verde processada no Paraná vem de ervais nativos ou sombreados. Nota-se que o valor de $60 \%$ corresponde ao percentual médio dos núcleos. Considerando a média do Estado, calculada com base no número de unidades de cada núcleo, tem-se um resultado ainda maior, onde $70,1 \%$ da erva-mate processada nos ervais paranaenses proviriam de ervais nativos ou sombreados. Este valor está próximo ao encontrado no trabalho de Deser (2001), onde é citado o valor de $75,63 \%$ como a participação dos ervais nativos ou sombreados na produção do Estado.

Os núcleos de Guarapuava, Irati e União da Vitória, que respondem por cerca de $2 / 3$ da produção de erva-mate verde no Paraná, são justamente os que possuem maior participação da erva-mate de ervais sombreados no volume processado. Nesses Núcleos os ervais sombreados respondem por mais de $3 / 4$ da erva-mate processada.

TABELA 3 - Origem da erva-mate verde quanto ao tipo de erval (\% do volume processado). Table 3 - Green erva-mate origin in relation with the type of erva crop (\% of the processed volume).

\begin{tabular}{|l|c|c|}
\hline \multicolumn{1}{|c|}{ Núcleo Regional } & $\begin{array}{c}\text { Erval nativo ou sombreado } \\
\text { (\%) }\end{array}$ & $\begin{array}{c}\text { Erval cultivado ou de pleno sol } \\
\text { (\%) }\end{array}$ \\
\hline Cascavel & 42,5 & 57,5 \\
Curitiba & 62,0 & 38,0 \\
Francisco Beltrão & 34,0 & 66,0 \\
Guarapuava & 75,0 & 25,0 \\
Irati & 78,5 & 21,5 \\
Ivaiporã & 41,2 & 58,8 \\
Laranjeiras do Sul & 33,6 & 66,4 \\
Pato Branco & 77,5 & 22,5 \\
Ponta Grossa & 72,0 & 28,0 \\
União da Vitória & 84,0 & 16,0 \\
Média & 60,0 & 40,0 \\
Estado do Paraná* & 70,1 & 29,9 \\
\hline
\end{tabular}

* Média ponderada, considerando o número de unidades por Núcleo.

A concentração na produção de ervamate verde e de unidades ervateiras nos municípios destes núcleos pode estar associada à oferta de erva-mate de ervais nativos/sombreados. As unidades cancheadoras estão instala- das nos municípios desses Núcleos para obter matéria-prima de qualidade diferenciada originada pelas condições dos ervais sombreados, influência destacada por Mazuchowski (2000). 
Os ervais nativos ou sombreados representam o perfil clássico ou tradicional da atividade ervateira, sendo esses explorados desde o início da atividade no Estado. Essa situação pode explicar ainda a colheita concentrada na safra, um paradigma no manejo dos ervais nativos.

\section{Conclusões}

O fornecimento de erva-mate para a indústria ervateira no Paraná apresenta algumas características bem definidas.

- A demanda por erva-mate para chimarrão com cor verde acentuada levou a ampliação do período de colheita, realizada em duas épocas, safra e safrinha. Entretanto, esta mudança não alterou significativamente o sistema, pois a maior parcela do volume processado provém do período de safra, média de $68 \%$;

- A maior parte da erva-mate verde processada nas indústrias é comprada de fornecedores (cerca de 80\%); e o remanescente vem de ervais próprios;

- No que se refere ao tipo de erval, os nativos ainda respondem pela maior fração (60\%) da erva-mate verde processada no Paraná. As regiões com maior produção são também as que possuem maior participação da erva-mate de ervais sombreados no volume processado.

Assim, pode-se afirmar que o setor industrial ervateiro trabalha com erva-mate nativa, colhida na safra e comprada de fornecedores, mostrando que pouco mudou na estrutura do setor nos últimos séculos, mantendo-se o perfil clássico ou tradicional da atividade ervateira.

\section{Referências}

ANDRADE, F. M. de Diagnóstico da cadeia produtiva da Ilex paraguariensisSt. Hill, Erva-Mate. São Mateus do Sul: Fundo Brasileiro para a Biodiversidade, 1999.

BOEGER, M. R. T. et al. Efeito das diferentes condições de luz e concentrações de nitrogênio sobre a estrutura foliar de Ilex paraguariensis St. Hil. In: CONGRESSO SUL-AMERICANO DA ERVAMATE, 3., Chapecó. 2003. Anais... Chapecó: EPAGRI, 2003. CD-ROM.
BRUMOVSKY, L A.; PERALTA, J. M.; FRETES, R. M. Contenido de fibra alimentaria en infusiones de yerba mate en diferentes épocas del año. In: CONGRESSO SUL-AMERICANO DA ERVA-MATE, 3., Chapecó, 2003. Anais... Chapecó: EPAGRI, 2003. CD-ROM.

CARDOZO JUNIOR, E. L et al. Variação no teor de cafeina em dezesseis progênies de erva-mate (Ilex paraguariensisst. hil.) cultivadas em três municípios do Paraná. In: CONGRESSO SUL-AMERICANO DA ERVA-MATE, 3., Chapecó, 2003. Anais... Chapecó: EPAGRI, 2003. CD.

COELHO, G. C.; RACHWAL, M.; SCHNORRENBERGER, E.; SCHENKEL, E. P. Efeito do sombreamento sobre a sobrevivência, morfologia e química da erva-mate. In: CONGRESSO SULAMERICANO DA ERVA-MATE, 2, 2000, Encantado: Reunião Técnica da Erva-Mate, 3., Encantado, 2000. Anais... Porto Alegre: Edição dos Organizadores, 2000. p. 6-12.

DESER- Departamento de Estudos Sócio-Econômicos Rurais. A cadeia produtiva da Erva-Mate. Informativo de Conjuntura Agrícola e Comercialização do Alto Uruguai. Curitiba, n. 3, p. 13. Set/Out 2001.

DUARTE, F.; WASZCZYNSKYJ, N. Análise Sensorial de extratos de erva-mate: seleção e treinamento de julgamentos. In: CONGRESSO SUL-AMERICANO DA ERVA-MATE, 2., , Encantado, 2000: Reunião Técnica da Erva-Mate, 3., Encantado, 2000. Anais... Porto Alegre: Edição dos Organizadores, 2000. p. 101-104.

HOPPE, M.; KARNOPP, E.; MEDRADO, M. J. Ervamate: diagnóstico e perspectivas de desenvolvimento. In: PREFEITURA MUNICIPALDEVENÂNCIO AIRES. Erva-mate: diagnóstico e perspectivas de desenvolvimento. Venâncio Aires: Prefeitura Municipal, 1996. p. 7-22.

INSTITUTO DE QUÍMICA AGRÍCOLA. Contribuição para o estudo da região ervateira. Rio de Janeiro, RJ: Ministério da Agricultura, 1944. p. 130. (Memória, n. 6).

MAZUCHOWSKI, J. Z.; MACCARI JUNIOR, A.; SILVA, E. T. da Influência de diferentes condições de radiação solar sobre o crescimento morfológico da erva-mate (Ilex paraguariensis St. Hil.). In: CONGRESSO SUL-AMERICANO DA ERVA-MATE, 
3., Chapecó, 2003. Anais... Chapecó: EPAGRI, 16 a 19 de novembro de 2003. CD-ROM.

MAZUCHOWSKI, J. Z. Alternativas para incremento da produção de ervais nativos. In: CONGRESSO SUL-AMERICANO DA ERVA-MATE, 2., Encantado, 2000. Reunião Técnica da Erva-Mate, 3., Encantado, 2000. Anais... Porto Alegre: Edição dos Organizadores, 2000. p. 6-12.

MAZUCHOWSKI, J. Z.; RUCKER, N. G. A. Diagnóstico e alternativas para a Erva-Mate Ilex paraguariensis. Curitiba: Secretaria de Estado da Agricultura e do Abastecimento, 1993.

. Prospecção tecnológica da cadeia produtiva da Erva - Mate. Curitiba: Secretaria de Estado da Agricultura e do Abastecimento, 1996.

PARANÁ - Secretaria da Agricultura e do Abastecimento do Paraná. Erva-mate: prospecção tecnológica da cadeia produtiva. Curitiba: SEAB, 1997.
REISSMANN, C. B. et al. Avaliação das Exportações de Macronutrientes pela Exploração da Erva-Mate. DOCUMENTOS, v. 15, p. 128-140, 1985.

RUCKER, N. G. A. A cor no controle de qualidade em erva-mate - Ilex paraguariensis A. St. Hil. In: CONGRESSO SUL-AMERICANO DA ERVA-MATE, 2., Encantado, 2000. Reunião Técnica da Erva-Mate, 3., Encantado, 2000. Anais... Porto Alegre: Edição dos Organizadores, 2000. p. 97-98.

VALDUGA, A. T.; FINZER, J. R. D.; MOSELE, S. H. Processamento de Erva-Mate. Erechim: EdiFAPES, 2003.

Recebido: 07/03/2005

Aprovado: 30/06/2005 